\title{
IMPACTOS DAS EMISSOES ATMOSFERICAS DA PRODUÇÃO DE VAPOR PARA INJEÇÃO EM CAMPOS MADUROS
}

\author{
P. H. E. EVARISTO ${ }^{1}$, C. E. M. JERÔNIMO ${ }^{2}$ e R.G. TEIXEIRA ${ }^{3}$ \\ ${ }^{1}$ Universidade Potiguar, Graduando em Engenharia de Petróleo e Gás. \\ ${ }^{2}$ Engenheiro de Processamento, PETROBRAS. Doutor em Engenharia Química. Professor. \\ ${ }^{3}$ Universidade Potiguar, Graduando em Engenharia de Petróleo e Gás. \\ E-mail para contato: p.paulo22@ hotmail.com
}

\begin{abstract}
RESUMO - Neste trabalho é realizado um estudo comparativo do coque verde de petróleo, com três combustíveis atualmente utilizados (óleo diesel, óleo combustível e o gás natural) no fornecimento de energia para produção de vapor para injeção em campos de petróleo maduros. O estudo consistiu no levantamento dos aspectos relativos à poluição atmosférica gerada por cada matriz, os níveis de confiabilidade que envolvem os cenários, as restrições de limpeza e manutenção que a operação individualizada de cada sistema possui e os níveis de insalubridade que são expostos os trabalhadores que atuam na manipulação direta desses combustíveis. Com base nas variáveis observadas foi possível desenvolver um mapa de vantagens e desvantagens para utilização do coque verde de petróleo, como alternativa energética na produção de vapor para injeção em campos de petróleo maduros. Os resultados obtidos demonstraram perdas nas variáveis técnicas e ambientais com a utilização do coque verde de petróleo, entretanto, com expressiva vantagem econômica. Porém, as restrições dos elevados investimentos poderiam inviabilizar os estudos de retorno econômico da referida mudança.
\end{abstract}

Palavras-chave: coque verde de petróleo. Gás natural. Gases de efeito estufa. Inventário de emissões.

\section{INTRODUÇÃO}

O atual cenário de produção de petróleo brasileiro onshore apresenta inúmeras dificuldades, entre as principais o fato dos campos serem classificados como maduros (em função do longo período de exploração). Consequentemente apresentam altos níveis de produção de água associada, um sério aspecto ambiental para ser gerenciado, em função da destinação final a ser aplicada para esse tipo de subproduto.

A água produzida, como comumente é denominada, apresenta inúmeras restrições de disposição em corpos d'água, requisitando um tratamento complexo e quase sempre de alto custo. Surgem as alternativas de disposição direta no solo, na camada superficial, entretanto alguns autores alertam para os riscos associados a essa operação. Entre as diferentes alternativas de tratamento e reutilização, a que atualmente consiste na principal solução dada a este resíduo, é a injeção em elevadas profundidades, como forma de auxiliar no processo de manutenção dos níveis de pressão do reservatório, e consequentemente aumentarem o fator de recuperação dos poços. 
Entretanto, segundo Cordeiro et al (2007), por conta da injeção de água em larga escala, em muitos poços maduros ocorrem danos ao reservatório, que atua como um meio filtrante, pois a água injetada muitas vezes contém gotas de óleo, particulados, material orgânico e mineral. Estes danos refletem diretamente na permeabilidade do reservatório nas proximidades do poço de injeção.

A geração do vapo é geralmente obtida por meio da instalação de geradores de vapor com a passagem da água por tubos, que são aquecidos pela chama direta na sua superfície. As chamas são obtidas por diferentes fontes de combustível, no Brasil restrito ao óleo diesel, ao óleo combustível de baixo ponto de fluidez e ao gás natural.

Entretanto, a atual matriz de combustíveis adotada sofre com a escassez frente a usos mais nobres, inclusive priorizados pela legislação brasileira, conforme descreve ANP (2012). O diesel tem a necessidade de importação continuada, havendo inúmeros projetos de ampliação nas diferentes refinarias do Brasil. O óleo combustível tem sua produção cada vez mais reduzida, em função dos avanços nas tecnologias de refino. E o gás natural possui inúmeras limitações logísticas no seu fornecimento e apresentam fins mais nobres, em especial na geração de polímeros, conforme relata Mariano (2005).

Diante desse quadro surge a necessidade da busca de alternativas economicamente viáveis para atenuar tal cenário. Entre as mais vislumbradas, não apenas para este fim, mas em todo o segmento industrial, é a utilização do coque verde de Petróleo. Visto que esse produto apresenta um baixo custo e representa uma tendência do aumento na sua disponibilidade, sobretudo, com a entrada em operação de novas unidades de coqueamento retardado no Brasil (2012).

O coque é um combustível que surge no cenário mundial devido à necessidade de se obter um combustível que atendesse a necessidades do processo de industrialização que se iniciou na Inglaterra no início do século XVIII. Abraham Darby ferreiro da cidade de Birmingham solucionou esse problema substituindo o carvão vegetal pelo carvão de coque (obtido a partir do carvão mineral de hullha) na fusão do ferro, originando assim um combustível com um alto potencial calorífico para o alto-forno. Dessa forma permite melhorar a qualidade e aumentar a produção. Essa substituição melhorou significativamente o problema da escassez de combustível existente nesse período, conforme cita Vieira (2009). Entretanto, para uma mudança radical na matriz energética da produção de vapor a partir de água produzida se faz necessário avaliar os riscos e impactos associados dessa medida, sejam estes, fatores que envolvem a confiabilidade, manutenção de equipamentos ou relacionados aos aspectos ambientais, visto que tal combustível tende a elevar os níveis de poluentes atmosféricos.

Diante desse quadro legal brasileiro, e as constantes cobranças para o desenvolvimento de acordos internacionais para o abatimento dos níveis de emissões, tais quais os protocolos e acordos: Quioto (INPE, 2012) e Copenhagen (SCIENCEBLOG, 2012), surgem a necessidade de aferição dos níveis de emissões nos processos de combustão, antes da utilização e investimentos nessa mudança.

A legislação brasileira, relativa aos níveis de emissões atmosféricas para fontes fixas (CONAMA 436/2011) possui o mesmo caráter determinístico adotado para águas e efluentes hídricos e estabelece severos limites de controle para diferentes agentes poluentes. Tais níveis devem ser utilizados como referência para correlação ao inventário de emissões, e torna-se possivelmente um elemento restritivo para a utilização da matriz do coque.

Como a concentração de poluentes está fortemente relacionada às composições dos combustíveis, torna-se mandatório a avaliação simulada dos níveis de emissões, em especial correlacionada com as informações relativas às fontes geradoras, os percentuais de enxofre e outros 
componentes químicos, a capacidade calorífica, os níveis de compostos nitrogenados e a qualidade dos níveis de excesso de oxigênio e temperatura de queima. Diante desse cenário, avaliar os impactos associados pelos diferentes combustíveis que compõe a matriz energética da produção de petróleo para injeção em campos de petróleo, sobretudo, pela necessidade constante de otimizar os custos associados se torna um elemento importante na gestão desse segmento.

Neste trabalho é realizado um estudo comparativo do coque verde de petróleo, com três combustíveis atualmente utilizados (óleo diesel, óleo combustível e o gás natural), de forma a levantar os aspectos relativos à poluição atmosférica gerada por cada matriz, os níveis de confiabilidade que envolve os cenários, as restrições de limpeza e manutenção que a operação individualizada de cada sistema possui e os níveis de insalubridade que são expostos os trabalhadores que atuam na manipulação direta desses combustíveis. Com base nas variáveis observadas foi possível desenvolver um mapa de vantagens e desvantagens para utilização do coque verde de petróleo, como alternativa energética na produção de vapor para injeção em campos de petróleo maduros.

\section{METODOLOGIA}

\subsection{Modelo de Geração de Vapor}

O estudo foi desenvolvido considerando um sistema de geração de vapor de 250.000 BTUs/h, necessários na produção de cerca de 50.000 barris de petróleo por dia. Os equipamentos foram considerados com bom estado de conservação e o cenário atual foi considerado como adaptado para queima de gás natural e óleo combustível.

O sistema considerado para produção de vapor é composto por uma câmara de combustão, com troca de calor por irradiação térmica da chama aplicada à tubulação por onde circula a água produzida tratada. Após a etapa de radiação as correntes trocam calor com os gases exaustos, em uma estrutura convectiva de permuta de energia.

O tratamento da água produzida, para atendimento aos níveis de qualidade requeridos, consiste na remoção primária das frações remanescentes de óleo, seguida de flotação e polimento por meio de resinas catiônicas e aniônicas.

Não foi considerada a utilização de sistemas de queima do tipo LOW-NOX, sendo avaliado o cenário para equipamentos disponíveis no mercado para três diferentes fornecedores. Os níveis de consumo requerido para cada cenário foi considerado conforme dados da Tabela 1, obtidos das correlações das eficiências de queima e capacidade calorífica (e densidade) de cada combustível estudado.

Tabela 1 - Dados relativos ao consumo de combustível em cada cenário avaliado.

\begin{tabular}{cccc}
\hline $\mathbf{N}^{\mathbf{0}}$ ref. & Tipo de Combustível & Consumo de combustível & Unidade \\
\hline 11 & Óleo Diesel & $6.552 .000,0$ & Litros \\
12 & Óleo Combustível residual & $10.656 .000,0$ & Litros \\
18 & Coque de petróleo & $17.143,2$ & Toneladas \\
40 & Gás Natural & $13.744 .800,0$ & $\mathrm{~m}^{3}$ \\
\hline
\end{tabular}




\subsection{Inventário de Emissões}

Os protocolos de cálculo para determinação dos gases de efeito estufa (GEE), NOx, SOx, MP etc., seguiram a metodologia GHG PROTOCOL desenvolvida pelo Centro de Estudos em Sustentabilidade da EAESP, e publicada em FGV (2009).

O GHG Protocol foi desenvolvido pelo World Resources Institute (WRI) em parceria com o World Business Council for Sustainable Development (WBSCD). A ferramenta oferece diretrizes para contabilização de GEE, com caráter modular e flexível e neutralidade em termos de políticas ou programas. A metodologia do GHG Protocol é compatível com as normas ISO e com as metodologias de quantificação do Painel Intergovernamental de Mudanças Climáticas (IPCC), e sua aplicação no Brasil acontece de modo adaptado ao contexto nacional.

As relações utilizadas pelo sistema GHG Protocol para as simulações são descritas na Tabela 2. Para o caso do SOx foi utilizada a relação mássica de 1:2, em função da concentração de enxofre presente nos combustíveis, ou seja, um simples balanço de massa. Contudo, foi possível o a obtenção do inventário comparativo entre as fontes no cenário com os quatro combustíveis avaliados.

Tabela 2 - Protocolos de cálculo para determinação de poluentes, GHG Protocol.

\begin{tabular}{cccc}
\hline $\mathbf{N}^{\mathbf{0}}$ ref. & $\mathbf{C O}_{\mathbf{2}}(\mathbf{k g} / \mathbf{u n})$ & $\mathbf{C H}_{\mathbf{4}}(\mathbf{k g} / \mathbf{u n})$ & $\mathbf{N}_{\mathbf{2}} \mathbf{O}(\mathbf{k g} / \mathbf{u n})$ \\
\hline 11 & 2,63 & 0,00011 & 0,00002 \\
12 & 3,11 & 0,00012 & 0,00002 \\
18 & $3.424,91$ & 0,10538 & 0,02108 \\
40 & 2,07 & 0,00004 & 0,00000 \\
\hline
\end{tabular}

\section{Resultados e Discussões}

Os resultados comparativos para os quatro combustíveis avaliados por meio da taxa de produção anual de poluentes atmosféricos foram obtidos para os componentes: metano, dióxido de carbono, óxidos de nitrogênio e óxido de enxofre.

Na Figura 1 são apresentados os dados para a emanação de metano, um dos principais componentes impactantes do efeito estufa. Nos resultados obtidos observa-se uma entre níveis de 400 a $1800 \mathrm{~kg}$ de metano por ano, nas diferentes matrizes. Tendo-se resultados mais expressivos para a utilização do coque. Esse fato se deve à queima incompleta do referido combustível, que emana para a atmosfera frações residuais deste e outros hidrocarbonetos.

Em termos comparativos observa-se que ocorre um aumento de cerca de $300 \%$ quando comparado à modificação do gás natural para o coque verde de petróleo. Em termos do comparativo entre óleo combustível e diesel, existe uma diferenciação de cerca de 90\%, mesmo sendo combustíveis bastante similares. Entre os óleos e o coque verde de petróleo o efeito adverso do uso do último é próximo a $100 \%$ superior.

Logo, a mudança na matriz energética para o coque verde de petróleo é notoriamente um prejuízo nesta variável, favorecendo a contribuição aos constituintes do efeito estufa e outros prejuízos ligados ao aumento da concentração de metano na atmosfera. 


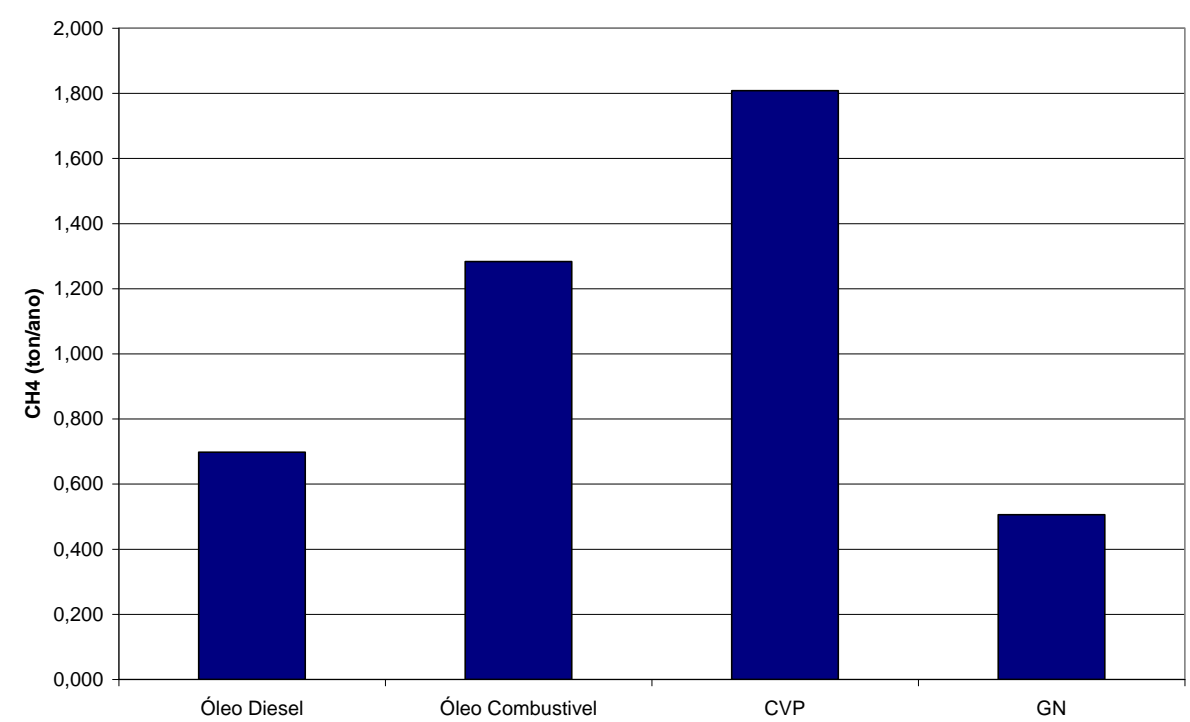

Figura 1. Níveis Globais emissões de $\mathrm{CH}_{4}$ nos cenários considerando os quatro combustíveis estudados.

Na Figura 2 são apresentados os dados para as simulações do GHG Protocol para a produção de $\mathrm{N}_{2} \mathrm{O}$, constituinte de grande impacto na produção de chuvas ácidas, destruição da camada de ozônio, além efeitos relacionados às mudanças climáticas.

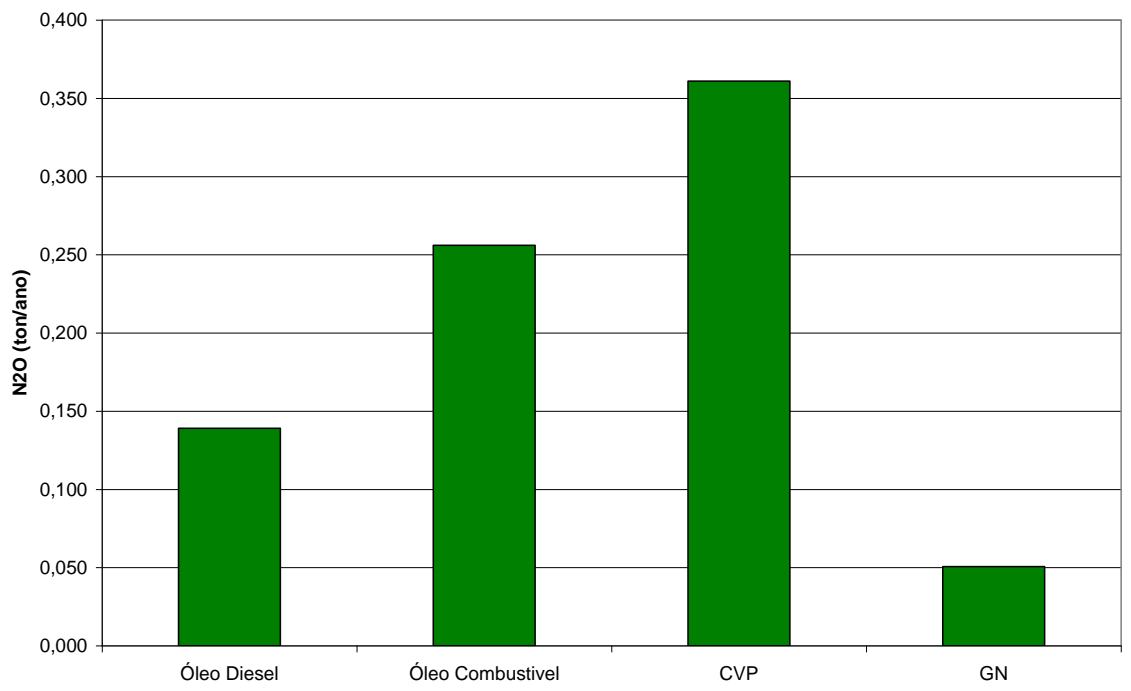

Figura 2. Níveis Globais emissões de N2O nos cenários considerando os quatro combustíveis estudados.

Observou-se neste cenário um aumento considerável na mudança comparativa entre gás natural e o coque verde de petróleo, sendo um impacto ambiental de grande proporção. Visto que se tem um aumento de 50 para mais de 350 toneladas desse poluente, em termos percentuais cerca de $700 \%$ de aumento. Logo, potencializa-se a presença de micro-climas e danos pela maior acidificação das chuvas, pela produção em proporções relativas às condições climáticas de ácidos nítricos. 


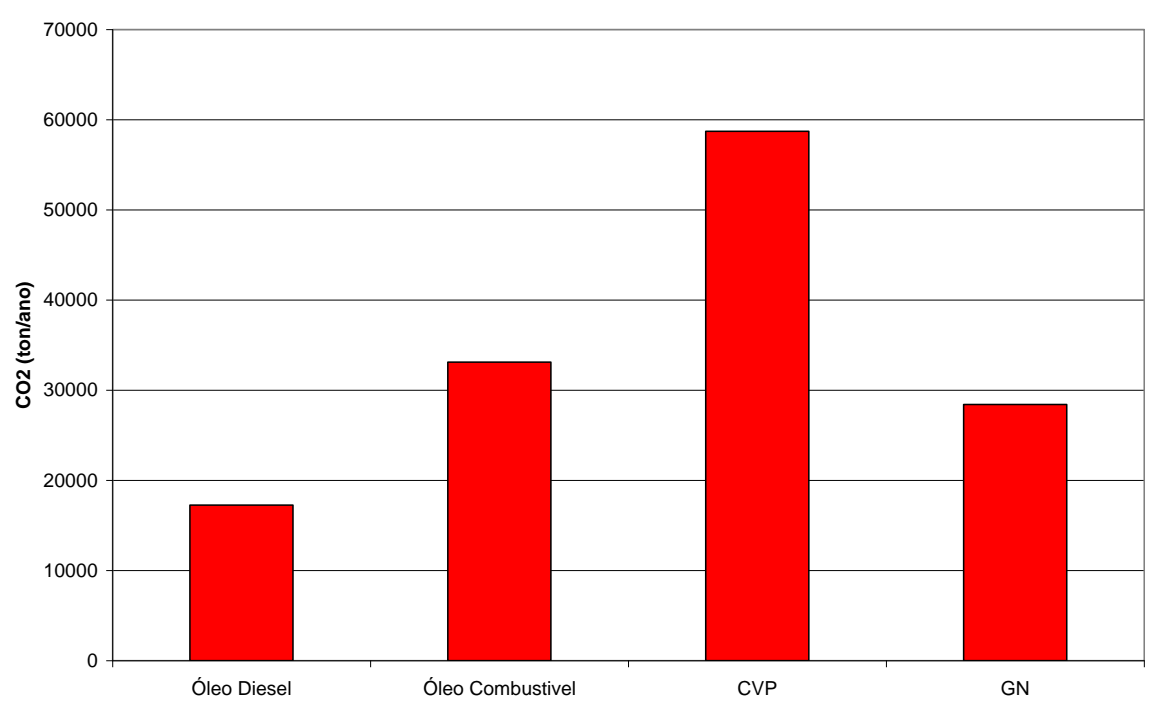

Figura 3. Níveis Globais emissões de $\mathrm{CO} 2$ nos cenários considerando os quatro combustíveis estudados.

Na Figura 3 são apresentados os resultados para os parâmetros de queima direta, ou melhor, dióxido de carbono. Visto que é o componente oriundo da fonte de carbono, e com a reação com o oxigênio é então produzido.

Observou-se, ainda, um cenário diferenciado nesta simulação, visto que a compensação das capacidades caloríficas concedem ao diesel os melhores índices de emanação de gases de efeito estufa. Entretanto, as limitações de custos e disponibilidade para outros fins mais nobres limitam sua difusão. Tal comportamento já é descrito na literatura, e dentre os casos Oliveira et al (2011), comenta sobre tal possibilidade, em função da combinação de variáveis adversas, como está.

Na Figura 4 é apresentado um comparativo entre o $\mathrm{CO}_{2 \mathrm{eq}}$ e os custos associados ao consumo do combustível estudado. Observa-se que o coque verde petróleo apresenta o menor valor de consumo, entretanto, para o pior cenário em termos ambientais. O gás natural, entretanto, apresentase num patamar médio de emissões e inferior aos demais óleos em termos de custos.

O efeito combinado dos componentes das emissões atmosféricas é freqüentemente analisado, para tal faz-se a equivalência química e numérica, por meio de relações com a massa molar. O parâmetro obtido desse somatório é o $\mathrm{CO}_{2 \text { eq }}$, dióxido de carbono equivalente, e consiste na potencialidade da emissão em produzir efeito estufa. Na Figura 5 são apresentados os resultados para a comparação com os níveis de óxidos de enxofre, tendo-se uma escala bastante desproporcional, visto que no caso do gás natural quase não se apresenta presença de tal constituinte. No cenário do coque, tende-se a maximizar efeitos derivados das chuvas ácidas, em função da elevada concentração. Em mecanismo descrito por CNTL (2006), para ocorrência e dano de tal fenômeno. 


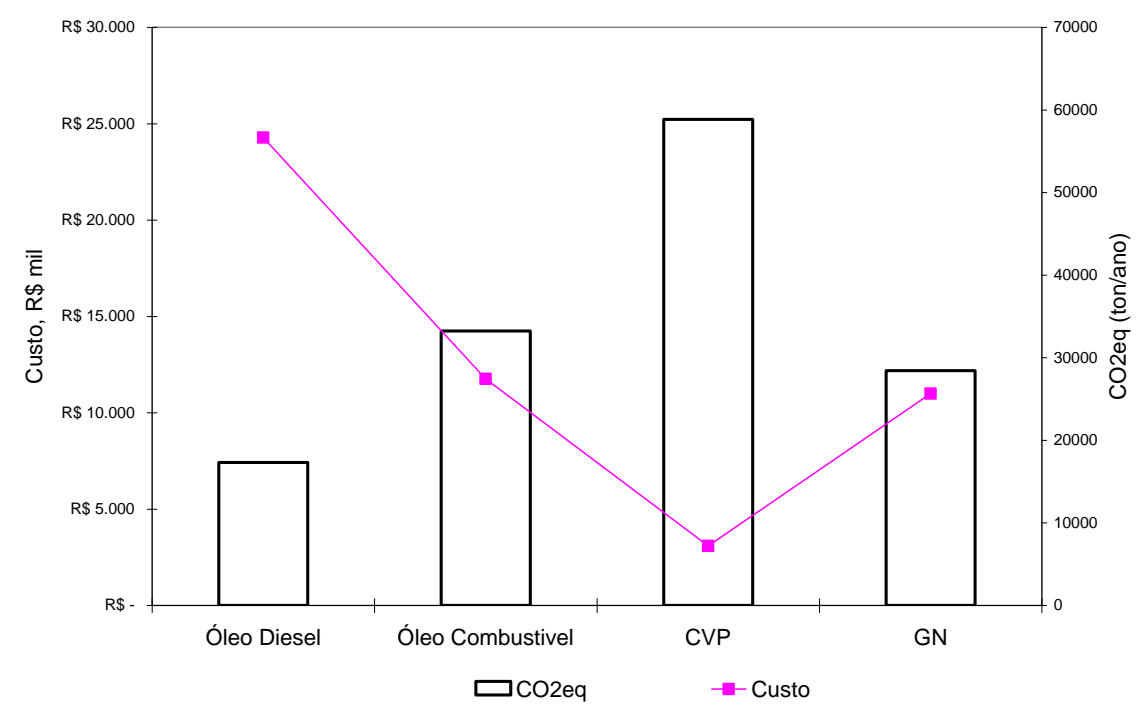

Figura 4. Correlação de custos e emissões atmosféricas para os combustíveis avaliados.

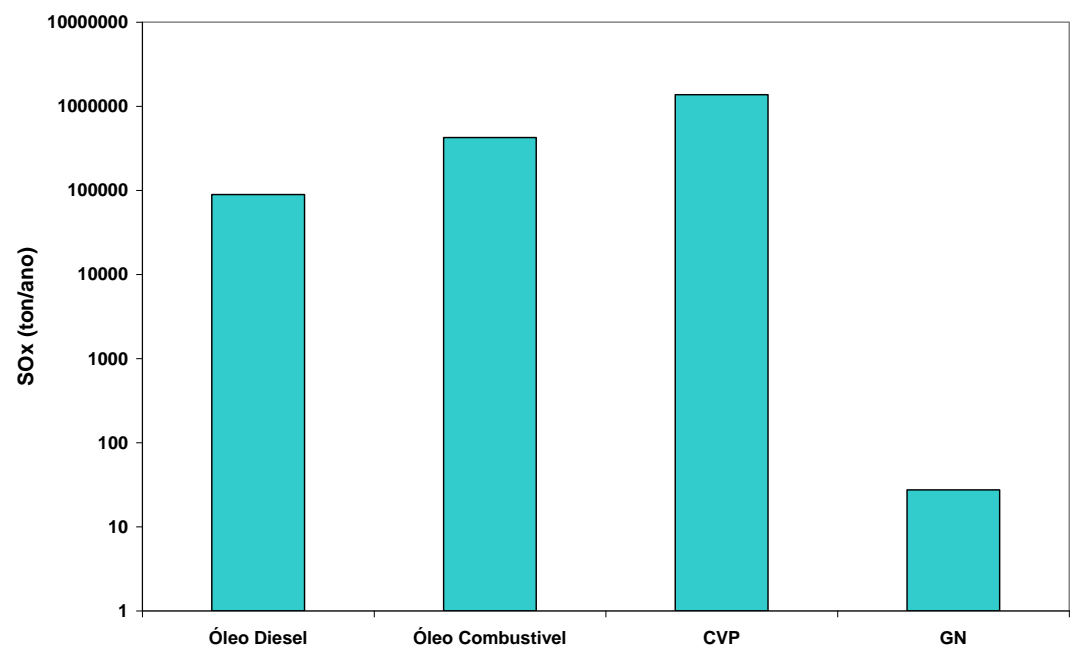

Figura 5. Níveis Globais emissões de $\mathrm{SO}_{\mathrm{x}}$ nos cenários considerando os quatro combustíveis estudados.

Logo, conclui-se que em termos ambientais, considerando todos os parâmetros analisados não há ganhos com a substituição do gás natural pelo coque. A substituição do gás natural pelo óleo diesel apresenta ganhos diretos, porém, quando analisada toda a cadeia associada não se vislumbram grandes viabilidades.

\section{CONCLUSÕES}

Considerando o estudo comparativo para adaptação dos cenários de combustíveis para a produção de vapor a partir de água produzida, o gás natural apresenta-se como a fonte de energia mais apropriada, por acoplar os melhores resultados em termos ambientais, técnicos e econômicos de forma combinada. Não se observou vantagens técnicas e ambientais na substituição e utilização 
do coque verde de petróleo para tal fim, com exceção do menor custo associado. Entretanto, uma ressalva deve ser feita que tal custo operacional reduzido seria compensado pelo maior investimento inicial, considerando-se a necessidade de sistemas de abatimento de emissões e preparo do combustível para pulverização, além de uma maior estrutura de acondicionamento e estocagem.

O indicador de qualidade foi considerado uma ferramenta aceitável para aferir o comparativo de vantagens e desvantagens, entretanto, um melhor detalhamento e objetividade nos critérios de pesos auxiliará na aplicação mais vasta da ferramenta. O GHG Protocol demonstrou uma ferramenta adequada para estudos comparativos, apresentando resultados lógicos e aderentes a estudos semelhantes descritos na literatura.

\section{REFERÊNCIAS}

ANP - AGENCIA NACIONAL DE PETROLEO. Acessível em: <http://www.anp.gov.br/?id=400>. Acesso em: 20/03/2012.

CNTL. CENTRO NACIONAL DE TECNOLOGIAS LIMPAS. Manual de Implantação de Programas de Produção Mais Limpa. Mimeo. Porto Alegre, 2006.

CONSELHO NACIONAL DE MEIO AMBIENTE - CONAMA. RESOLUÇÃO $\mathrm{N}^{\circ}$ 436, de 22/12/2011 Estabelece os limites máximos de emissão de poluentes atmosféricos para fontes fixas instaladas ou com pedido de licença de instalação anteriores a 02 de janeiro de 2007.

CORDEIRO, A. F. et al. Simulação da injeção de água em reservatórios empregando CFD. In: $4^{\circ}$ PDPETRO, Campinas, SP. 2007.

GOMES, E. A. Tratamento combinado de água produzida de petróleo por eletroflotação e fotofenton. Dissertação de Mestrado. UFSE, Aracaju-SE. 2009.

MARIANO, J. B. Impactos Ambientais do Refino de Petróleo. Rio de Janeiro: Interciência, 2005.

MINISTÉRIO DO MEIO AMBIENTE - MMA. Brasil anuncia metas de mitigação de emissão de gases-estufa para a $\quad$ COP-15. Disponível em: $<$ http://www.mma.gov.br/sitio/index.php?ido=ascom.noticiaMMA\&codigo=5324>. Acesso em: 10/04/2012.

NOVATO, A. P. S. et al. Levantamento e priorização de oportunidades de produção mais limpa para os recursos hídricos em refinarias de petróleo. Monografia de Especialização. UERJ. Rio de Janeiro - RJ. 2006.

OLIVEIRA, P. S. et al. Avaliação da mudança da matriz energética da REMAN visando reduzir as emissões de GEE. Premio Qualidade Amazonas - FIEAM. Apresentação Final. Manaus, AM. 2011. 